\title{
Clinical and serological evolution in chronic Chagas disease patients in a 4-year pharmacotherapy follow-up: a preliminary study
}

\author{
Mônica Coelho Andrade ${ }^{[1]}$, Maria de Fátima Oliveira ${ }^{[2]}$, Aparecida Tiemi Nagao-Dias ${ }^{[2]}$, \\ Ivo Castelo Branco Coêlho ${ }^{[1]}$, Darlan da Silva Cândido ${ }^{[2]}$, Erlane Chaves Freitas ${ }^{[1]}$, \\ Helena Lutéscia Luna Coelho ${ }^{[3]}$ and Fernando Schemelzer Moraes Bezerra ${ }^{[1], ~[2], ~[4] ~}$
}

[1]. Departamento de Patologia e Medicina Legal, Faculdade de Medicina, Universidade Federal do Ceará, Fortaleza, CE. [2]. Departamento de Análises Clínicas e Toxicológicas, Faculdade de Farmácia, Universidade Federal do Ceará, Fortaleza, CE. [3]. Departamento de Farmácia, Faculdade de Farmácia, Universidade Federal do Ceará, Fortaleza, CE. [4]. Departamento de Saúde Comunitária, Faculdade de Medicina, Universidade Federal do Ceará, Fortaleza, CE.

\begin{abstract}
Introduction: The role of trypanocidal therapy in the chronic phase of Chagas disease remains controversial. Methods: A total of 13 patients with chronic Chagas disease were treated with benznidazole $(5 \mathrm{mg} / \mathrm{kg} /$ day $/ 60$ days $)$ and surveyed via antibody measurement and conventional electrocardiogram over the course of 4 years. Results: The antibody titers were significantly reduced after 4 years $(\mathrm{p}<0.05)$. Most of the patients showed maintenance of the initial clinical picture (electrocardiographic), with the exception of 4 cases. Conclusions: Although trypanocidal therapy in the chronic phase of Chagas disease was of limited effectiveness, we believe that it is beneficial in treating these patients.
\end{abstract}

Keywords: Benznidazole. Chagas disease. Pharmacotherapy follow-up.

One hundred years after its discovery, Chagas disease (CD) remains a public health problem in Latin America'. In Brazil, it is estimated that two to three million people are infected by vectorial transmission or through blood transfusion. The prevalence of the disease is less than $0.2 \%$. The oral transmission route has also become relevant $\mathrm{t}^{2,3}$.

One of the main manifestations of CD is cardiac involvement ${ }^{4}$, which occurs most frequently in people between 20 and 59 years of age and represents the leading cause of disability and mortality associated with the disease ${ }^{5}$. The only drug available for the treatment of Chagas disease in Brazil is benznidazole $(\mathrm{Bz})^{6}$.

There is no doubt that the use of Bz during the acute phase of CD is beneficial; however, there are no convincing data in the medical literature that indicate that this specific treatment is effective in preventing the progression of chronic $\mathrm{CD}$ (except for the BENEFIT project, currently in progress) ${ }^{7}$.

Given these facts and due to the scarcity of publications on this topic, we evaluated cardiac and serological parameters in patients with chronic $\mathrm{CD}$ treated with $\mathrm{Bz}$ in a 4-year pharmacotherapy follow-up. The study included 13 patients

Address to: Dr. Fernando Schemelzer Moraes Bezerra. Depto Análises Clínicas e Toxicológicas/FFOE/UFC. R. Capitão Francisco Pedro 1210, 60430-370 Fortaleza, CE, Brasil.

Phone: 5585 3366-8242

e-mail: bezerra@ufc.br

Received 21 May 2012

Accepted 20 December 2012 with chronic $\mathrm{CD}$, aged 27-60 years, living in different municipalities of the State of Ceará, Brazil, with prescriptions for $\mathrm{Bz}(5 \mathrm{mg} / \mathrm{kg}$ per day for 60 days). The patients underwent clinical and laboratory assessments in the cardiology outpatient clinic at the Hospital Universitário Walter Cantídio (HUWC), Ceará, Brazil, and in the Chagas Disease Research Laboratory. After providing informed written consent, the patients were followed for 4 years (2006-2009). In one patient (patient 2), the treatment was interrupted 50 days after the first dose due to an episode of paresthesia (Table 1).

The first serum sample collection was performed prior to the beginning of therapy in 2006, and the subsequent three collections were performed at 1-year intervals. The samples were stored at $-20^{\circ} \mathrm{C}$ until use. Semi-quantitative analyses of the anti-Trypanosoma cruzi immunoglobulin $\mathrm{G}(\mathrm{IgG})$ in the serum samples were performed using an enzyme immunoassay (Biomérieux, Brazil). The results were expressed in optical density (OD) units (minus blank). In the serological follow-up, the titer was considered to be: unchanged when the OD from the last collected sample increased or decreased by less than 1.5 -fold compared to the OD at the first analysis; progressive when the OD increased by $\geq 1.5$-fold compared to the first analysis; and regressive when the OD decreased by $\geq 1.5$-fold compared to the first analysis, as proposed by Zauza et al. ${ }^{8}$. A conventional electrocardiogram was also performed before (2006) and after treatment (2009). Holter monitoring was used as necessary to clarify obscure cases.

A paired $t$ test was used to compare the geometric means of the anti-T. cruzi IgG titers over time. The level of statistical significance was 0.05 . 
TABLE 1 - Epidemiological, serological, and electrocardiographic findings in chronic chagasic patients over 4 years of follow-up.

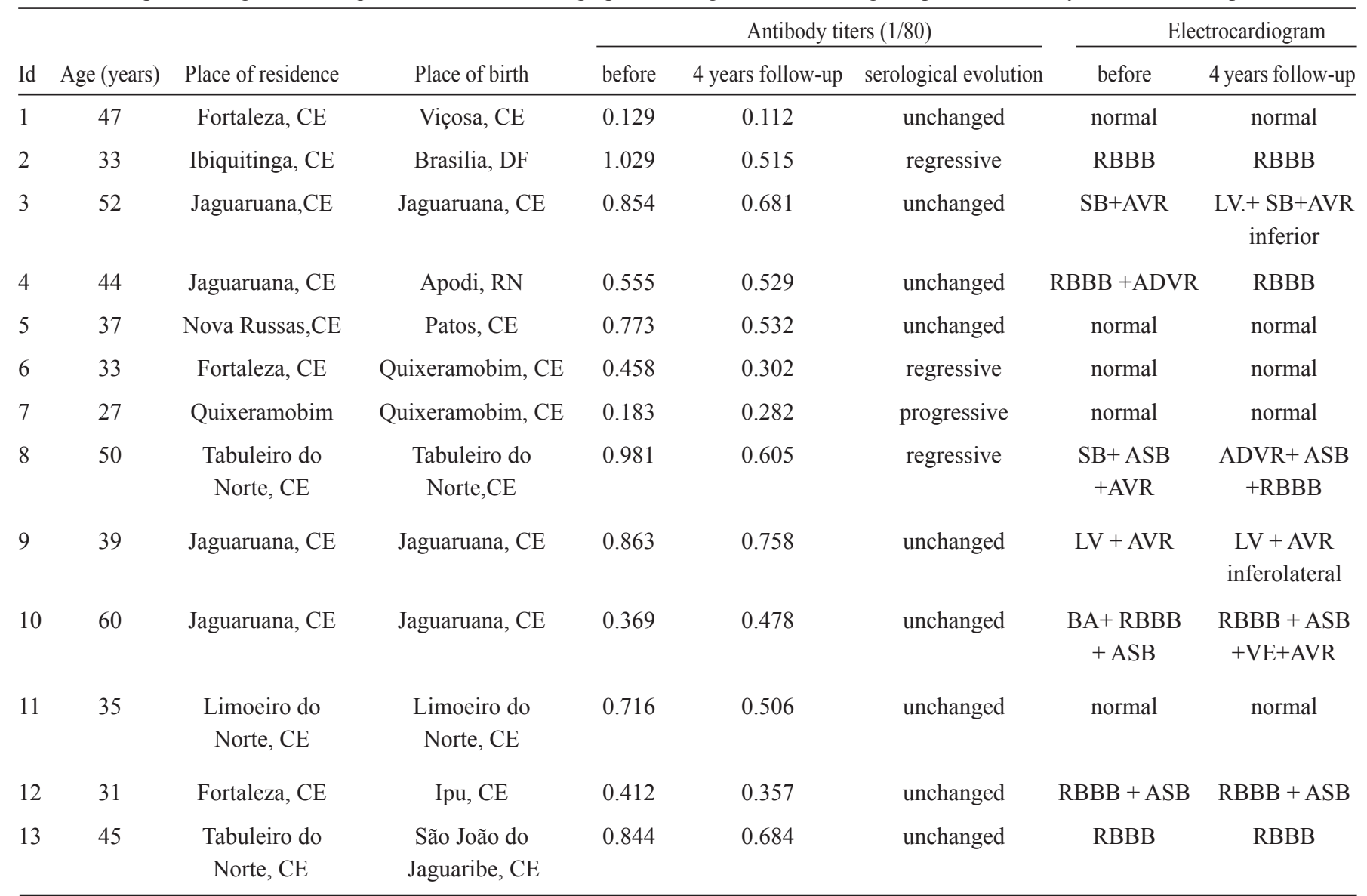

Id: identy number; CE: Ceará; DF: Distrito Federal; RN: Rio Grande do Norte; RBBB: right bundle branch block; SB: sinus bradycardia; AVR: alteration of ventricular repolarization; LV: low voltage; ADVR: amendment diffuse ventricular repolarization; ASB: anterosuperior divisional block; BA: bradyarrhythmia; VE: ventricular extrasystole.

The study was approved by the Research Ethics Committee of HUWC on 23 October 2006 with the code 053060 and on 19 August 2010 under protocol number 014.03.1.

Antibody titers remained unchanged in $9(69.2 \%)$ patients, regressive in $3(23.1 \%)$ patients, and progressive in $1(7.7 \%)$ patient. Antibody titers significantly decreased $(p<0.05)$ between the baseline (2006) and at the 4-year follow-up (2009) (paired $\mathrm{t}$ test), as shown in Figure 1.

In general, the majority of patients tended to maintain the initial clinical picture, with a normal electrocardiogram $(E K G)$ before and after treatment or the same or similar electrocardiographic findings before and after treatment (Table 1). However, 4 cases merit further comment. Patient 2 required a pacemaker implantation due to an increase in breaks, as detected by Holter monitoring. Before treatment, patient 3 had an ejection fraction (EF) of 56, which showed improvement $(E F=72)$ shortly after the use of Bz. Patient 8 evolved RBBB (right bundle branch block) even after the use of Bz. Patient 10 required a dual-chamber implantable cardioverter defibrillator in 2010 (after the end of the study period). These results reinforce the need for a longer follow-up period of investigation because 4 years of follow-up was shown to be insufficient to evaluate cardiac outcomes in chronic chagasic patients.

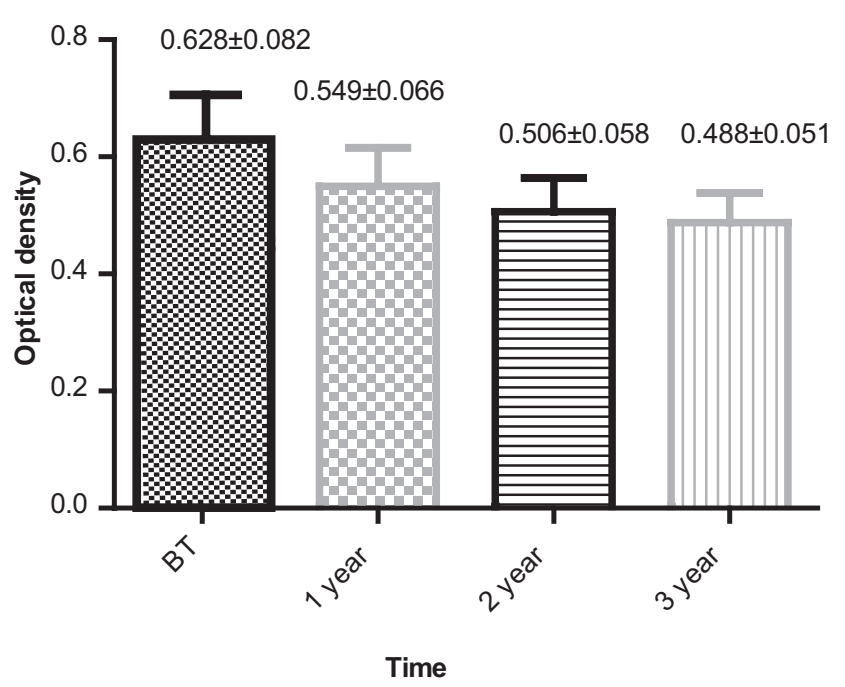

Average \pm SE (standard error) $-\mathrm{BT}$ (before treatment, 2006) Paired $t$ test (BT vs 3 year), $p<0,05$

FIGURE 1 - Decrease in serum anti-Trypanosoma cruzi antibodies in 13 chronic chagasic patients before and after a 4-year pharmacotherapy follow-up. Average $\pm \mathrm{SE}$ (standard error) - BT (before treatment, 2006); Paired t test (BT versus 3 years), $\mathrm{p}<0.05$. 
The trypanocidal treatment of the chronic phase of $\mathrm{CD}$ remains controversial because there are few longitudinal experimental or clinical studies regarding this disease phase 9 . Experts indicate that the time required to achieve seronegative status varies and depends on the disease phase - for instance, 5 to 10 years for a recent chronic phase and over 20 years for a chronic phase of long duration ${ }^{10}$. Fabbro et al. ${ }^{11}$, in a 21-year follow-up study, investigated chronic chagasic patients treated with benznidazole or nifurtimox $(\mathrm{n}=54)$ and untreated patients $(\mathrm{n}=57)$ aged 17 to 46 years. Of the patients who were treated with benznidazole or nifurtimox, $37 \%$ became seronegative, while the untreated patients remained seropositive. A 10year follow-up study conducted with 140 untreated chronic chagasic patients aged 10 to 70 years demonstrated that $57.9 \%$ remained serologically unchanged, $37.1 \%$ exhibited serological progression, and only $5 \%$ exhibited decreases in antibody titers ${ }^{8}$. Our findings revealed a significant reduction of antibody titer in patients treated with benznidazole over 4 years of follow-up.

Perez-Molina et al. ${ }^{12}$ performed a systematic review and meta-analysis of benznidazole use in $\mathrm{CD}$. These authors verified that benznidazole use was associated with an 18 -fold increase in the probability of a good response to therapy. According to their review, although the data suggest a beneficial effect of drug treatment, the efficacy of this therapy in the late chronic phase remains controversial. This uncertainty is largely due both to differences in the studied populations, endpoints, and followup periods and to the fact that almost all information about treatment in the late chronic phase came from non-randomized studies. Our results indicate that treatment of the chronic phase of CD may be beneficial for the patients; decreased anti-T. cruzi IgG titers and maintenance of the initial clinical picture were observed in most of the patients. Therefore, we believe that an extended follow-up study with a greater number of patients will be important to confirm our results.

\section{CONFLICT OF INTEREST}

The authors declare that there is no conflict of interest.

\section{REFERENCES}

1. Petherick A. After years of neglect, Brazil takes aim at Chagas disease. Focus on Brazilian Biomedicine. Nature Medicine 2011; 17:1174.

2. Silva EM, Rocha MOC, Silva RC, Paixão GC, Buzzati H, Santos NA, et al. Estudo clínico-epidemiológico da doença de Chagas no distrito de Serra Azul, Mateus Leme, centro-oeste do Estado de Minas Gerais. Rev Soc Bras Med Trop 2010; 43:178-181.

3. Silveira AC. Os novos desafios e perspectivas futuras do controle. História sobre a Doença de Chagas no Brasil. Rev Soc Bras Med Trop 2011; 44 (supl II):122-124.

4. Prata A, Dias JCP, Coura JR. Os primórdios da doença. História sobre a Doença de Chagas no Brasil. Rev Soc Bras Med Trop 2011; 44 (supl II):6-11.

5. Coura JR, Vinãs PA. Chagas disease: a new worldwide challenge. Nature 2010; 465:S6-S7.

6. Pontes VMO, Souza Junior AS, Cruz FMT, Coelho HLL, Nagao-Dias AT, Coelho ICB, et al. Reações adversas em pacientes com doença de Chagas tratados com benzonidazol, no Estado do Ceará. Rev Soc Bras Med Trop 2010; 43:182-187.

7. Coura JR, Borges-Pereira J. Chronic phase of Chagas disease: why should it be treated? A comprehensive review. Mem Inst Oswaldo Cruz 2011; 106:641-645.

8. Zauza PL, Pereira JB. Níveis sericos de IgG anti-Trypanosoma cruzi na evolução da cardiopatia chagásica crônica, no período de 10 anos. Rev Soc Bras Med Trop 2001; 34:399-405.

9. Marín-Neto JA, Rassi Jr A, Avezum Jr A, Mattos AC, Rassi A. The beneficit trial testing the hypothesis that trypanocidal therapy is beneficial for patients with chronic Chagas heart disease. Mem Inst Oswaldo Cruz 2009; 104 (supl I):319-324.

10. Ministério da Saúde. Secretaria de Vigilância em Saúde. Consenso Brasileiro em doença de Chagas. Rev Soc Bras Med Trop 2005; 38 (supl III):1-29.

11. Fabbro DL, Streiger ML, Arias ED, Bizai ML, Del Barco M, Amicone NA. Trypanocide treatment among adults with chronic Chagas disease living in Santa Fé City (Argentina), over a mean follow-up of 21 years: parasitological, serological and clinical evolution. Rev Soc Bras Med Trop 2007; 40:1-10.

12. Pérez-Molina JA, Pérez-Ayala A, Moreno S, Fernández-González MC, Zamora J, López-Velez R. Use of benznidazole to treat chronic Chagas' disease: a systematic review with a meta-analysis. J Antimicrob Chemother 2009; 64: 1139-1147. 